\title{
GEOGRAFIA FÍSICA CRÍTICA, TOPOCLIMATOLOGIA ANDINA E O EXTRATIVISMO MINEIRO NO SALAR DE ATACAMA
}

\author{
ROMERO, Hugo - hromero@uchilefau.cl \\ Universidad de Chile \\ PAIVA, Júlio César - paivajulio2@gmail.com \\ Universidade Federal de Minas Gerais / UFMG \\ OPAZO, Dustyn - dustyn.opazo@gmail.com \\ Universidad de Chile
}

\begin{abstract}
RESUMO: A imposição de redes, estratégias e práticas de produção territorial por estados e empresas transnacionais estão reduzindo a resiliência das comunidades no que diz respeito aos eventos climáticos mais extremos. Nesse contexto, o presente artigo explora a atual luta das comunidades indígenas que resistem à mineração de lítio no Salar de Atacama, em meio ao Deserto do Atacama. A extracção de água através de poços profundos nos graus superiores do relevo, além de seu uso para produzir e industrializar o lítio estão ameaçando a sobrevivência de algumas comunidades andinas representantes da etnia atacameña. A partir da Geografia Física Crítica e da Climatologia Cultural, pretende-se contrapor o cosmopolitismo dos modelos de mudança do clima e sua falta de especificidade geográfica, sem a qual não é possível compreender a epistemologia, a ontologia e as metodologias de adaptação a tais mudanças. A climatologia geográfica cultural pode aprender muito a partir das formas, processos e estruturas de adaptação às mudanças e variabilidades apresentadas pelas comunidades que, em seu cotidiano, enfrentam os desafios causados pelas perturbações dos sistemas naturais e socioeconômicos em seus territórios, reconfigurando a disposição e o acesso aos recursos tradicionais. Caso não haja uma integração e coprodução entre as áreas científicas e populares, o conhecimento local dos topoclimas, as formas de adaptação às mudanças e variabilidades climáticas, e até mesmo as próprias comunidades tradicionais correm o risco de desaparecer devido à agressividade e à crescente presença de atores externos de natureza colonizadora.
\end{abstract}

PALAVRAS-CHAVES: Lítio, Comunidades Indígenas, Conflitos Socioambientais, Adaptação, Mudanças Climáticas

CRITICAL PHYSICAL GEOGRAPHY, ANDEAN TOPOCLIMATOLOGY AND THE MINING EXTRATIVISM IN ATACAMA SALT

ABSTRACT: The imposition of networks, strategies and practices of territorial production by states and transnational corporations are reducing the resilience of communities with respect to the most extreme climatic events. In this context, this article explores the current struggle of indigenous communities who resist to lithium mining in the Atacama Salt Flat, in midst of the Atacama Desert. The extraction of water through deep wells in the upper grades of relief, besides their use to produce and industrialize lithium, are threatening the survival of some Andean communities representing the Atacameña ethnic group. From Critical Physical Geography and Cultural Climatology, it is intended to counteract the cosmopolitanism of climate change models and their lack of geographic specificity, without which it is not possible to understand the epistemology, the ontology and the methodologies of adaptation to such changes. Cultural geographic climatology can learn a great deal from the forms, processes and structures of adaptation to the changes and variabilities presented by the communities that, in their daily lives, face the challenges caused by the disturbances of the natural and socioeconomic systems in their territories, reconfiguring the disposition and the access to traditional resources. If there is no integration and coproduction between scientific and popular areas, local knowledge of topoclimates, ways of adapting to climate changes and variabilities, and even 
traditional communities themselves are in danger of disappearing due to the aggressiveness and increasing presence of external actors of a colonizing nature.

KEYWORDS: Lithium, Indigenous Communities, Socio-environmental Conflicts, Adaptation, Climate Change.

GEOGRAFÍA FÍSICA CRÍTICA, TOPOCLIMATOLOGÍA ANDINA Y EL EXTRATIVISMO MINERO EN EL SALAR DE ATACAMA

RESUMEN: La imposición de redes, estrategias y prácticas de producción territorial por parte de los estados y las empresas transnacionales están reduciendo la resiliencia de las comunidades en lo que respecta a los eventos climáticos más extremos. En este contexto, el presente artículo explora la actual lucha de las comunidades indígenas que resisten la mineralización del litio en el Salar de Atacama. La extracción de las aguas a través de pozos profundos ubicados en las secciones superiores de las cuencas de las montañas andinas, además de su uso para industrializar el litio, están amenazando la sobrevivencia de algunas de las comunidades indígenas representantes de la etnia atacameña. A partir de la Geografía Física Crítica y de la Climatología Cultural se pretende contrarrestar el cosmopolitismo de los modelos de Cambio Climático o su falta de especificidad geográfica, sin los cuáles no es posible comprender la epistemología, la ontología o la metodología de adaptación ante tales cambios. La Climatología Cultural puede aprender mucho de las formas, procesos y estructuras de adaptación a los cambios y variabilidades climáticas de parte de las comunidades, que en su cotidiano enfrentan los desafíos planteados por las perturbaciones de los sistemas ambientales y socioeconómicos en sus territorios, reconfigurando la posesión y acceso a los recursos tradicionales. Mientras no haya una co-producción e interacción entre las áreas científicas y populares, el conocimiento local de los topoclimas, los temas de adaptación a los cambios y variabilidades climáticas, y las propias comunidades tradicionales corren el riesgo de desaparecer debido a la agresividad y presencia creciente de actores externos de naturaleza colonizadora.

PALABRAS CLAVE: Litio, Comunidades Indígenas, Conflictos Socioambientales, Adaptación, Cambios Climáticos.

\section{GEOGRAFIA FÍSICA CRÍTICA E A TOPOCLIMATOLOGIA CULTURAL COMO CONCEITOS HÍBRIDOS FUNDAMENTAIS}

A Geografia Física Crítica emergiu como uma opção interessante e como uma resposta disciplinar à necessidade de superar a dicotomia geografia física geografia humana, a fim de recuperar relevância social para os desafios colocados pelo antropoceno e pelo capitoloceno, especialmente na América Latina (LAVE et al., 2014; TADAKI, 2017). A climatologia como componente da geografia física não pode ficar de fora da busca por explicações sócioeconômico-culturais que respondam pelas diferenças observadas nas paisagens geográficas de diferentes lugares, neste caso, destacando as situações das montanhas andinas por conta da variabilidade espacial e temporal de seus climas locais.

A geografia supracitada reconhece que os lugares constituem síntese de combinações indissociáveis entre natureza e sociedade, cujas explicações comprometem as relações particulares entre as variáveis da natureza, que no caso dos climas locais são comandadas pela chegada de massas de ar exógenas, suas transformações termo-hidrológicas in loco sob a influência ponderada da topografia, da altitude, da exposição e posição topológica das encostas e vales (LAVE et al., 2014; PRIETO, 2016; TADAKI, 2017). No entanto, os climas ou topoclimas locais também recebem a influência direta da cobertura e uso do 
solo, que por sua vez, está relacionada às atividades econômicas, sociais e culturais das comunidades locais. Estes últimos são ordenados por um sistema complexo de práticas produtivas, valores e princípios culturais, além de uma rede de interpretações e significados pertencentes aos domínios físico, material, metafísico e simbólico.

Os topoclimas, portanto, não são apenas manifestações locais das sequencias rítmicas em que se combinam os tipos de tempo em sua sucessão habitual sobre determinados lugares. Eles também correspondem às interpretações culturais em que se incluem conhecimentos (epistemologias), significados (ontologias) e formas de construí-los e desconstrui-los (metodologias) (HULME, 2015, 2017). Essas formas culturais, assim como toda expressão social, são o resultado do exercício do poder imposto por governos e classes dominantes como parte de múltiplas relações entre os habitantes dos lugares, seus espaços naturais e suas interações com outros lugares, estruturando redes topológicas visíveis e invisíveis entre seres vivos humanos e não humanos que ordenam os territórios de determinadas maneiras. O produto de múltiplos processos de tentativa/erro/negociações entre os atores, se transforma em aprendizagem social e memórias históricas que nos permitem imaginar o futuro e sustentar os mecanismos de mitigação e adaptação diante das mudanças climáticas.

O avanço da geografia física, da climatologia e de outros ramos como hidrologia, geomorfologia e glaciologia amplia os horizontes epistemológicos da disciplina, afastando-a de reducionismos equivocados e de métodos positivistas, cuja maior expressão corresponde à aplicação de modelos padronizados como os de mudança climática que carecem de um sentido de lugar e, com isso, de significância geográfica. Ao não considerar as especificidades locais, ou seja, subtraindo o conhecimento geográfico local, coloca-se em risco o desaparecimento da própria geografia física, diante do qual é necessário assumir posições inalienáveis de defesa disciplinar (LAVE et al., 2014; SLAYMAKER, 2017; GOUDIE, 2017). Isso se torna especialmente necessário tendo em vista a emigração de geógrafos físicos para outras disciplinas ou de sua própria recusa em fundamentar a natureza geográfica dos estudos sobre a atmosfera, hidrosfera, biosfera, pedosfera e criosfera. Dessa forma, é necessário contribuir para a fundamentação da natureza específica e integrativa da climatologia geográfica.

A serviço do conceito de lugar, a topoclimatologia não apenas ilustra a extraordinária complexidade e variabilidade espaço-temporal que a distribuição de temperaturas, chuvas, ventilação, umidade e pressão atmosférica, entre outras, alcança. Ela ilustra também a complexa rede de inter-relações que ligam o comportamento destes parâmetros físicos com outros componentes do sistema biogeofísico (POPKE, 2016). No entanto, as sociedades conhecem e explicam o clima não como fatos isolados sobre a água, solos, plantas, habitações e práticas produtivas. Elas reconhecem as mudanças espaço temporais do todo, diante das quais é necessário adotar estratégias de mitigação e adaptação como parte da vida cotidiana. Para isso, é essencial sistematizar as experiências históricas e suas projeções para o futuro (HULME, 2015, 2017).

$\mathrm{Na}$ escala local, no entanto, existe um complexo sistema de conhecimentos que alcança sua maior expressão no caso das comunidades 
indígenas de montanha, como ocorre com os povos Aymara e Quechua que habitam os vales e altiplanos da Cordilheira dos Andes no Equador, Peru, Chile e Argentina. Para estas culturas, que ocuparam por milênios a montanha andina e sobreviveram às múltiplas mudanças climáticas e perturbações socioecologicas, os climas locais são um componente fundamental do território, já que a vida depende deles e sua conservação e melhoria é o principal objetivo. Naturalmente, esse objetivo específico das comunidades difere substancialmente dos objetivos de outros atores sociais e, particularmente, das empresas extrativistas e suas alianças com as elites governantes e políticas.

Castree (2016) se perguntou por que e para quem o conhecimento geográfico é construído, e não hesitou, juntamente com Popke (2016) e Hulme (2017) em atribuir um profundo senso ético relacionado à virtude e à esperança das comunidades mais vulneráveis. Essa contribuição da geografia física parece ser imprescindível, já que muitas comunidades andinas enfrentam crescentes pressões pela desapropriação de seus recursos territoriais, especialmente do espaço e das águas superficiais e subterrâneas e de todos os componentes naturais e sociais envolvidos (ROMERO et al., 2017).

O ayllu corresponde ao conceito que liga em sum só lugar todas as dimensões da realidade: aos seres humanos e não humanos. Entre os primeiros estão os ancestrais e os deuses, destacando aqueles que representam todos os elementos do clima. Cada lugar tem deuses que simbolizam nuvens, ventos, chuvas, neves e tempestades. Todos eles dão origem a deusa água, que fertiliza a Pachamama ou deusa mãe terra, da qual dependem inúmeros seres vivos não humanos como as plantas, insetos, animais selvagens e domésticos. No ayllu, todos eles interagem mediante diálogos e interdependências que se expressam em diferentes linguagens e que devem ser conhecidos e compreendidos pela totalidade dos integrantes daquele lugar, com a finalidade de poderem responder a seus requerimentos mútuos e, desta maneira, evitar incompreensões ou fúrias que desencadeiam eventos extremos como secas, inundações e ondas de calor ou frio e que consequentemente ameaçam as distintas formas de vida (VAN KESSEL, 1992; ROMERO et al., 2017).

Todo esse conjunto de relações forma a Geografia Física Crítica dos territórios andinos e as diferentes fases históricas que compõem sua "genealogia territorial" (MÉNDEZ e ROMERO, 2018). Os processos de dominação territorial e aculturação aos quais os povos têm sido permanentemente submetidos, geram uma geografia em continua mudança e adaptação, não exclusivamente diante das mudanças climáticas (que os afetam muitas vezes), mas também a respeito da luta para manter suas características vernaculares e, através de sua cultura, as ordens territoriais que dispõem de espaços e acessos às diferentes paisagens e recursos territoriais. A ocupação destes lugares no tempo e no espaço é a principal resposta à variabilidade climática e representa sua principal forma de resiliência. Da mesma forma, a imposição dos poderes políticos que tentam substituir suas configurações territoriais com interpretações dominantes nas dimensões cognitiva, valorativa e metodológica é observada como uma interferência que deve ser rejeitada e que está na base dos conflitos socioterritoriais permanentes e proeminentes (ROMERO et al., 2018). As comunidades indígenas lutam contra as indústrias extrativas tais como a mineração, silvicultura, abastecimento de água potável, mercado imobiliário, instalações de produção de energia convencionais e não convencionais. 
Desta forma, a topoclimatologia não é só uma ciência pertencente à geografia física positivista que pode ser estudada através de modelos físicos e estatísticos, mas também é parte do sistema de vida dos povos indígenas e, portanto, de relações complexas que se estabelecem no lugar entre os seres vivos humanos e não humanos. Este conhecimento permite a subsistência em paisagens de alta complexidade e incerteza e não corresponde somente às aproximações (teorias, objetos e métodos) das ciências convenciones. Os objetos de análise estão relacionados com a vida prática e cotidiana das comunidades e têm a ver com suas formas de organização das práticas produtivas, com os sistemas de explicações dos fatos e, sobretudo, com o reconhecimento de múltiplas causas físicas e metafísicas (ROMERO et al., 2017).

A topoclimatologia andina dispõe de sistemas de prognósticos denominados señaleros que permitem predizer a ocorrência de eventos e períodos climáticos de alta relevância, tais como a presença de anos sucessivos de seca, tormentas e inundações e registro de ondas de calor e frio (VAN KESSEL e SALAS, 2002; ROMERO et al., 2018). Para longos períodos ou previsões de um ano para o outro, consultam a posição e transparência visual de constelações estrelares. Para as variações interanuais, o florescimento de determinadas plantas, o aparecimento de certos insetos ou pássaros e a constante observação das nuvens e direção dos ventos. Já para as sazonais, uma infinidade de indicadores naturais, biológicos e metafísicos. Esses señaleros, por sua vez, condicionam os pedidos que irão fazer em suas cerimônias religiosas que são uma amostra de sincretismo entre suas crenças ancestrais e as impostas durante a evangelização dos colonizadores católicos.

As celebrações comunitárias constituem momentos de intensa interação entre os integrantes do ayllu. São presididas pelas montanhas mais altas que controlam a paisagem da bacia andina, pelos deuses que intermediam as relações com os habitantes locais e a totalidade dos seres que as integram. Nestas celebrações, líderes comunitários validam seu poder com a ajuda de "yatires" ou sábios indígenas que se comunicam com os elementos e fatores climáticos através de observações e diálogos específicos, cujas linguagens se ensina de forma inter e intrageracional (GREBE 1990; VAN KESSEL, 1992; ROMERO et al. 2017, 2018). Uma geográfica crítica que não só compreende as formas de organização sociológica das comunidades indígenas andinas, mas que também contribui com seu conhecimento para respaldar os argumentos de defesa dos territórios socialmente construídos e baseados na comunidade evitando sua erosão cultural e extinção, representa um compromisso da climatologia de natureza não apenas cientifica, mas também de caráter ético e político (KERSHAW et al., 2014; TADAKI, 2017; SLAYMAKER, 2017). A geografia física que estuda lugares e territórios como um conjunto de relações entre sistemas biofísicos e socioculturais sob certas hegemonias políticas, responde mais plenamente aos desafios da sociedade e ao processo de descolonização do conhecimento (TADAKI e VAN DICK, 2014).

No entanto, também surge como uma necessidade da Geografia Física Crítica reinterpretar a topologia ligada etimológica e conceitualmente à topoclimatologia, além de se abrir às relações relevantes com outros ramos da geografia física, como ocorre com a hidrogeologia e a geomorfologia de bacias. $\mathrm{Na}$ verdade, as relações sociohidrológicas ou hidrológico-sociais e seus estudos de redes e territórios, constituem também o esforço de observar a água como um objeto híbrido que é conhecido, interpretado e gerido por sistemas 
sociopolíticos de dimensões variadas (LINTON, 2010; BOELENS, 2014; BOELENS et al., 2016, LINTON e BUDD, 2014). Estes sistemas vinculam os atributos físicos e químicos com os significados metafísicos e imateriais que conformam extensas redes de poder, que por sua vez, regulam a propriedade e uso por parte das comunidades e que se alinham permanentemente com as aspirações de considerá-la apenas um insumo produtivo, cujo uso e manejo deve ser controlado e regulado pelo mercado, como propõe a doutrina neoliberal de ampla e sustentada aplicação nos territórios latino-americanos (BABIDGE, 2016).

A transição do conceito do ciclo hidrológico para o ciclo hidrossocial corresponde a mais uma das respostas que a Geografia Física Crítica deve fornecer. No caso das comunidades andinas, suas bacias hidrográficas estão sendo fragmentadas e apropriadas em suas seções superiores, área exclusiva de chuva e acumulação de neve e, portanto, sede das zonas de acumulação de águas superficiais e infiltração de canais subterrâneos dos quais a disponibilidade de recursos hídricos de todo o sistema depende. Isso nos permite compreender não apenas o interesse dos atores exógenos em apropriar-se das fontes, mas também a sensibilidade dos ecossistemas ali localizados e seu significado como sede de todas as divindades por parte dos habitantes indígenas (BUDD, 2009, 2010).

Quem controla as áreas de captura na alta montanha controla a totalidade das redes hidrossociais, ou seja, controlam o destino e uso das águas nas seções média e baixa das bacias. A Geografia Física Crítica tem a obrigação de disponibilizar às comunidades os maiores esforços para conhecer detalhadamente os ciclos hidrológicos, incluindo os balanços hídricos e as redes e territórios hidrossociais envolvidos. Esse conhecimento é uma das principais assimetrias existentes entre o conhecimento local e o conhecimento especializado nas mãos de agentes de empresas e órgãos governamentais. A falta de informação pública e a ambiguidade prevalente sobre os déficits e equilíbrios dos balanços hídricos é uma das maiores injustiças ambientais observadas na região latino-americana. Tal situação é ainda mais grave tratando-se das relações entre a superfície terrestre, o subsolo e a atmosfera, cujo sistema concentra as trocas de energia, informação e movimentos que são quase completamente desconhecidos.

As comunidades indígenas, por não depender do conhecimento especializado e científico, assimilaram ao seu sistema de conhecimento as propriedades metafísicas que permitem cumprir com o objetivo principal: a manutenção e o fortalecimento das formas de vida, obviamente ameaçadas por conta da carência de água. A água é uma divindade e suas áreas de origem e jornada a jusante são outros deuses, ou seja, as ambiguidades produzidas por eventuais lacunas no conhecimento são compensadas por um sistema de crenças que mantém o controle da comunidade sobre a água nas mãos dos líderes locais, que sabem interpretar o comportamento destes recursos e impedir suas dificuldades de acesso (VAN KESSEL, 1992; BABIDGE, 2016; PRIETO, 2016). As comunidades andinas esperam dos geógrafos físicos respostas igualmente complexas nos aspectos epistemológicos, ontológicos e metodológicos, e não apenas na existência de conhecimento elaborado a partir do positivismo e do reducionismo científico. 
A bacia hidrográfica é antes de tudo uma complexa geoforma espacialmente integrada e interativa, que no caso das montanhas andinas, se constitui na mais importante ordem territorial. A geomorfologia andina é também uma sociogeomorfologia na medida em que as comunidades nativas reconhecem e defendem sua interpretação unitária e de interdependência entre as terras altas e baixas (ASHOMORE, 2015). Tal como acontece com toda a geografia física, são novamente híbridos territoriais que interagem com os seres humanos e não humanos que habitam os lugares. Os povos andinos dialogam com suas montanhas, com as terras e os solos, com os riachos, rios e nascentes e realizam doações e orações que satisfazem suas necessidades sob o conceito de reciprocidade ou cuidado mútuo. A Geografia Física Crítica dos povos andinos é profundamente humanista (HULME, 2017).

\section{TOPOCLIMATOLOGIA CULTURAL DAS COMUNIDADES ANDINAS}

A climatologia dos povos andinos faz parte de uma multi-escalaridade que associa de modo funcional e simbólico, não apenas as escalas próprias dos espaços regionais euclidianos, mas também, preferencialmente, redes topológicas e ontológicas que geram suas próprias espacialidades desde a vinculação entre os componentes biogeofisicos e culturais, no primeiro caso, até o real com o simbólico no caso das interpretações de seus significados. Historicamente, seus assentamentos foram deslocados sobre a bacia hidrográfica da Cordilheira dos Andes, que separa as influências áridas controladas pelo Oceano Pacífico das massas de ar úmido da monção amazônica, além das diferentes cargas de radiação solar, exposição às massas de ar, graus de continentalidade e presença de uso e cobertura vegetal (ROMERO et al., 2013; 2017; MENDONÇA et al., 2014).

A Figura 1 resume os topoclimas do norte do Chile caracterizados por faixas longitudinais correspondentes a níveis ecológicos controlados pela altura e pela topologia das bacias. Nos níveis baixos próximos à costa, predomina o deserto absoluto onde praticamente não há chuva registrada; há também encostas e vales da Depressão Intermediária, através dos quais, eventualmente, massas de ar oceânicas e continentais ligam as enseadas ao mar. Além disso, ocorrem sistemas de vales e declives da pré-cordilhera que marcam a transição entre o deserto interior e o de altitude. Nos setores mais altos predominam cordilheiras e altiplanos onde ocorrem depressões e serras. Nestas áreas, registra-se sazonalmente ilhas de calor e frio que atraem ou expulsam as comunidades pastoris que, por sua vez, tecem um complexo sistema espacial de assentamentos humanos e circuitos de transumância entre os níveis inferiores e superiores dos andes.

Van Kessel e Salas (2002), resumiram uma ampla gama de conhecimentos indígenas sobre os climas locais, incluindo não apenas objetos físicos e práticas produtivas, mas também lendas e interpretações simbólicas que associam suas variações espaço temporais com as atividades da vida cotidiana, representada particularmente pela produção agrícola-pastoril de subsistência. Tal relação constitui um hibrido natural-social que ordena uma topologia espaço temporal que associa fluxos diversos entre as zonas topoclimáticas. 
Nos casos analisados por Van Kessel e Salas (2002), Van Kessel (1992) e Grebe (1990), a interpretação rítmica dos climas identifica uma estação chuvosa (la para pacha) ou criação da vida, que abarca desde a primeira quinzena de novembro até o mesmo período em abril, quando se registram precipitações que podem ser eventualmente torrenciais acompanhadas de trovões, granizos e neve, e que possui alta variabilidade espacial. Em seguida, se desenvolve a estação de geadas (gasapacha ou chirawapacha), que se estende desde a segunda quinzena de abril até a primeira de agosto, onde os céus limpos favorecem a ocorrência de temperaturas baixas. Finalmente, registra-se também a estação seca (ch'akipacha) entre a segunda quinzena de agosto e a de novembro, quando alcança sua maior aridez devido à evaporação mais elevada.

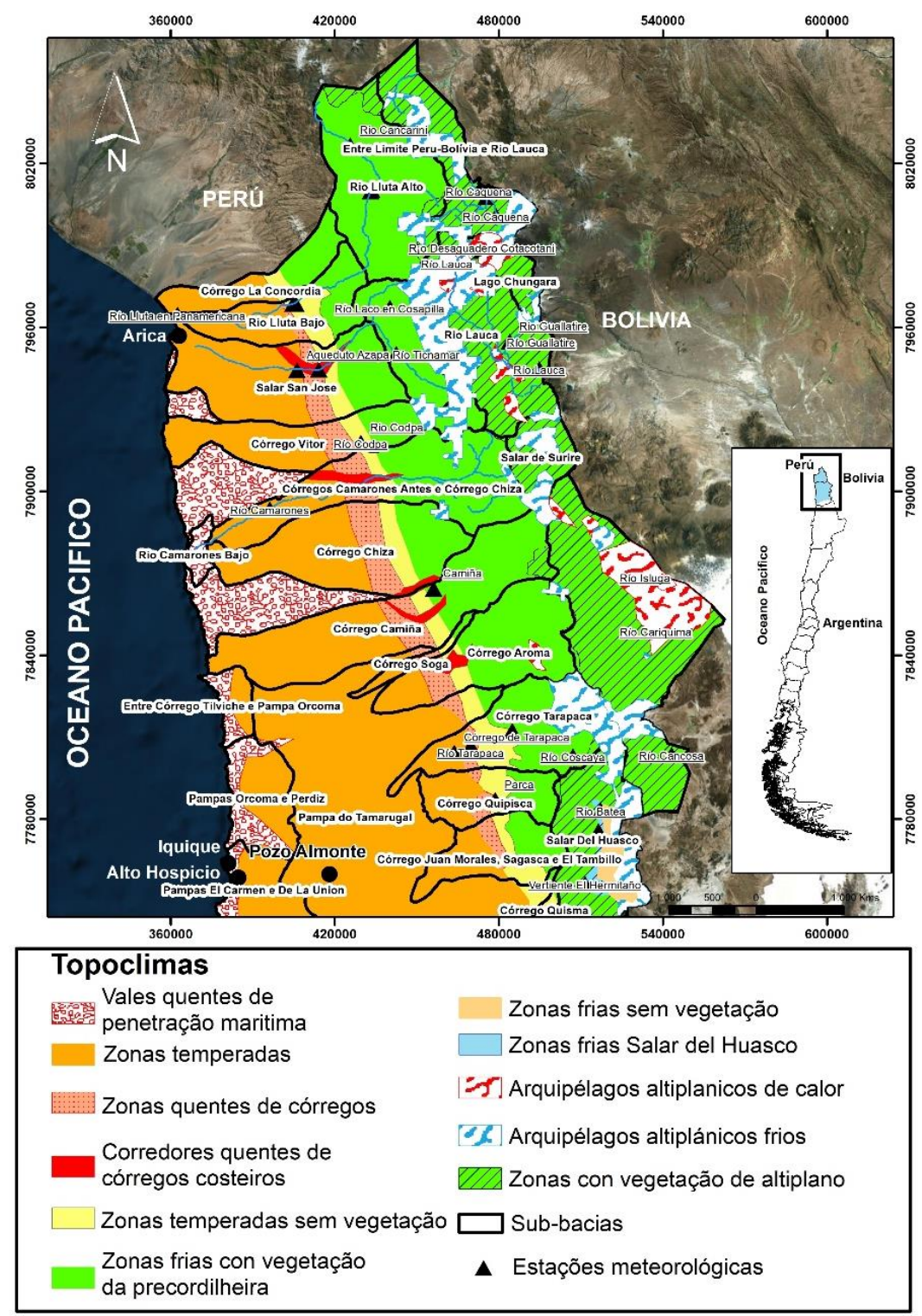

Figura 1 - Topoclimas do Deserto do Atacama na região norte do Chile.Fonte: DGA 2018, Centro de Estudios de Humedales (CEH) e Laboratorio de Medio Ambiente y Territorio do Departamento de Geografía da Universidad de Chile.

Ano 15 - Edição Especial - XIII Simpósio Brasileiro de Climatologia Geográfica - JUN 2019 
Considerando a alta variabilidade espacial e temporal dos climas andinos, os agricultores aymaras devem prever e calcular com a maior precisão possível, de acordo com as previsões realizadas com base em senãleros de curto, médio e longo prazo, o tempo de cultivo de suas lavouras, os sítios topoclimáticos mais aptos, as variedades mais adequadas e resistentes, bem como 0 desenvolvimento de técnicas para defender as culturas contra o excesso de umidade, seca, frio e ondas de calor. Para isso, eles mantêm sistemas de informação pré-colombianos baseados em dados empíricos e meta-empíricos que são complementados por uma organização dos territórios. Esta organização é projetada para dividir os riscos climáticos espaciais e sociais com base na apropriação de recursos pela comunidade, o que facilita o intercâmbio entre os níveis topoclimaticos complementarmente conectados (ZIMMERER, 2003; VAN KESSEL E SALAS, 2002).

Essas plataformas altitudinais são cultivadas simultaneamente onde acumulam calor tanto pela água armazenada, quanto por grandes rochas expostas à insolação. Estes terraços estão destinados, ademais, a reter e preservar o solo, provocando microturbulências nas camadas de ar sobrepostas e impedindo a acumulação de ar frio e danos às culturas causados pela geada. Para Van Kessel e Salas (2002), a criação da vida nas lavouras é o objetivo principal das comunidades. Sendo assim, estratégias tecnológicas empíricas e simbólicas se baseiam em mitos e rituais para dispersar e minimizar os riscos climáticos. Ademais, para estes autores:

\begin{abstract}
"El clima que es variable y diversificado, es un factor que juega un papel muy importante en la crianza de la vida en el medio natural andino, un papel positivo y favorecedor. La variabilidad y diversidad que se acentúa aún más con la presencia de heladas, sequías, granizadas e inundaciones, no es un impedimento para criar la vida; por el contrario, contribuye a su mayor diversificación" (Van Kessel e Salas, 2002:55).
\end{abstract}

Os fatores, elementos e produtos do clima correspondem aos Wak'as: a Mãe Terra (Pachamama), a mãe Iago (Qutamama), os Achachilas ou colinas protetoras (Mallkus e T'allas), o Intitata ou deus do sol, Anqari o do vento, Qasa deusa da geada, Supu-supuni da neve, entre muitos outros (VAN KESSEL e SALAS, 2002).

Não obstante, os componentes climáticos dentro da comunidade não têm existência própria em si mesmo como indivíduos, mas fazem parte de espaços relacionais (físicos e metafísicos), cujo diálogo e troca são criados mutuamente. "O diálogo com a troca de presentes e serviços entre os componentes da comunidade (seja grande, pequena ou familiar) é constitutivo e dá sentido à existência de cada um: é uma reciprocidade entre os seres e entre os grupos" (VAN KESSEL e SALAS, 2002: 60). A coexistência nessas redes não significa paz e harmonia pois as colinas, as águas, os fenômenos climáticos, todo o Wak'a e todos os componentes do Salla (seres vivos não humanos) têm seu gênio e seus caprichos, seus apetites e suas sensibilidades que devem ser respeitados. Portanto, os Runa (seres humanos) e os Wak'as (divindades) devem continuamente conversar, alimentar e nutrir um ao outro.

As cerimônias dedicadas à Pachamama reconhecem sua natureza viva e fazem parte de uma ontologia na qual seus componentes convergem através de 
signos: as plantas o fazem com os animais e ambos com os fenômenos atmosféricos (chuva, geada, granizo, nuvens, vento, arco-íris, tempestades, névoas), e com os astros (constelações, sol, lua, planeta, via láctea) (VAN KESSEL e SALAS, 2002). São mensageiros vivos (señaleros) que, para o povo andino, têm voz e boca e que, na forma de um coro polifônico permitem conhecer antecipadamente o comportamento e os ritmos internos da natureza. Eles não são indicadores objetivos, mas seres vivos, que conhecem o ritmo da vida de Pacha. "São sinais e cada um deles diz aos camponeses o que sabem, desde que estes saibam como falar com eles, perguntar e entender com a mesma sensibilidade e sutileza" (VAN KESSEL e SALAS, 2002: 88).

No diálogo com os señaleros, os agricultores andinos não pretendem conhecer as causas dos fenômenos climáticos, pois sabem, ancestralmente, que estes são consubstanciais ao meio ambiente andino e que devem ocorrer infalivelmente à medida que passam seus ciclos cósmicos e telúricos. O que interessa ao agricultor andino é saber, mediante a estes sinais, o caráter ou comportamento do clima, ou seja, com que particularidades ocorrerão as geadas, chuvas de granizo, secas e inundações durante o ciclo agrícola (VAN KESSEL e SALAS, 2002).

Para a região de Tarapacá foram compilados os principais aportes proporcionados por Van Kessel (1992) e Grebe (1990) e atualizados por Basure (2015), Roca e Venegas (2015), mediante a oficinas e entrevistas com representantes das comunidades de Pica, Collacagua, Lirima e Alto Camiña. Como exemplo, a Tabela 1, apresenta como os roedores são interpretados como señaleros climáticos por estas comunidades. 
Tabela 1 - Roedores como "señaleros" climáticos nas comunidades de Tarapacá, região norte do Chile

\begin{tabular}{|c|c|c|c|}
\hline $\begin{array}{c}\text { NOME } \\
\text { COMUM/NOME } \\
\text { CIENTÍFICO }\end{array}$ & $\begin{array}{l}\text { NOME EM } \\
\text { AYMARA }\end{array}$ & COMPORTAMENTO & $\begin{array}{l}\text { ÉPOCA DE } \\
\text { APARIÇÃO }\end{array}$ \\
\hline $\begin{array}{c}\text { Rato/ } \\
\text { Musmusculos }\end{array}$ & Achuku & $\begin{array}{c}\text { Quando entra nas estâncias ou } \\
\text { nas casas não é morta, deve ser } \\
\text { despachada. Quando fazem seus } \\
\text { ninhos em lugares altos, será um } \\
\text { ano chuvoso. }\end{array}$ & $\begin{array}{l}\text { O ano todo. } \\
\text { Praga em } \\
1973 .\end{array}$ \\
\hline $\begin{array}{l}\text { Tuco tuco/ } \\
\text { Ctemonusrobustus }\end{array}$ & Tuto tuco & $\begin{array}{c}\text { Cavam de baixo da terra e } \\
\text { comem raízes. Cavam mais } \\
\text { quando vai ser um ano seco. } \\
\text { Quando entra nas estâncias, } \\
\text { indica que vai ser um ano } \\
\text { chuvoso. }\end{array}$ & $\begin{array}{l}\text { O ano todo em } \\
\text { Pampa del } \\
\text { Tamarugal e } \\
\text { sua } \\
\text { quantidade } \\
\text { não diminuiu. }\end{array}$ \\
\hline $\begin{array}{l}\text { Rato de montanha/ } \\
\text { Auliscomyssublimis }\end{array}$ & Wanco & $\begin{array}{l}\text { Anuncia a chuva que cai entre } \\
\text { janeiro e fevereiro. Em março e } \\
\text { abril, procura raízes nas colinas. } \\
\text { Hoje se vê menos. }\end{array}$ & Março-abril \\
\hline $\begin{array}{c}\text { Vizcacha/ } \\
\text { Lagidiumviscacia }\end{array}$ & Wisk'acha & $\begin{array}{l}\text { Quando é um ano ruim, com } \\
\text { escassez de pasto, é mais gordo. } \\
\text { Acasala em setembro. Eles são } \\
\text { observados entre campo úmidos } \\
\text { e secos. Vivem nas rochas. } \\
\text { Quando escava e chafurda, } \\
\text { significa um bom ano produtivo. }\end{array}$ & $\begin{array}{c}\text { As crias } \\
\text { começam nos } \\
\text { meses de } \\
\text { outubro e } \\
\text { novembro. } \\
\text { Se pode ver } \\
\text { durante todo o } \\
\text { ano. }\end{array}$ \\
\hline
\end{tabular}

Fonte: Adaptado de Van Kessel (1992); Grebe (1990); Basure (2015), Roca e Venegas (2015).

Finalmente, a Figura 2 é uma ilustração modificada da forma em que os aymaras da região de Tarapacá desenham iconicamente seu calendário anual de atividades agrícolas e pastoris, que constitui a maneira em que as variações climáticas são incorporadas na vida cotidiana. Em sua representação original, como círculo, apresenta uma primeira partição que começa com a chegada do ano novo andino no solstício de inverno até culminar no solstício de verão. Ademais, o calendário apresenta uma segunda partição simétrica que corresponde ao custeo (pastos em níveis mais baixos no relevo) e ao pasteo (pastos em níveis mais altos). O primeiro indica as estações do ano em que as comunidades estão obrigadas a concentrar suas atividades de supervivência nas terras baixas, escapando das baixíssimas temperaturas registradas nas cordilheiras e altiplanos. Por outro lado, com a aproximação do solstício de verão, é possível ascender até as terras altas arriando o gado de auquénidos (Ihamas e alpacas) até os lugares de pastoreio (veranadas). 


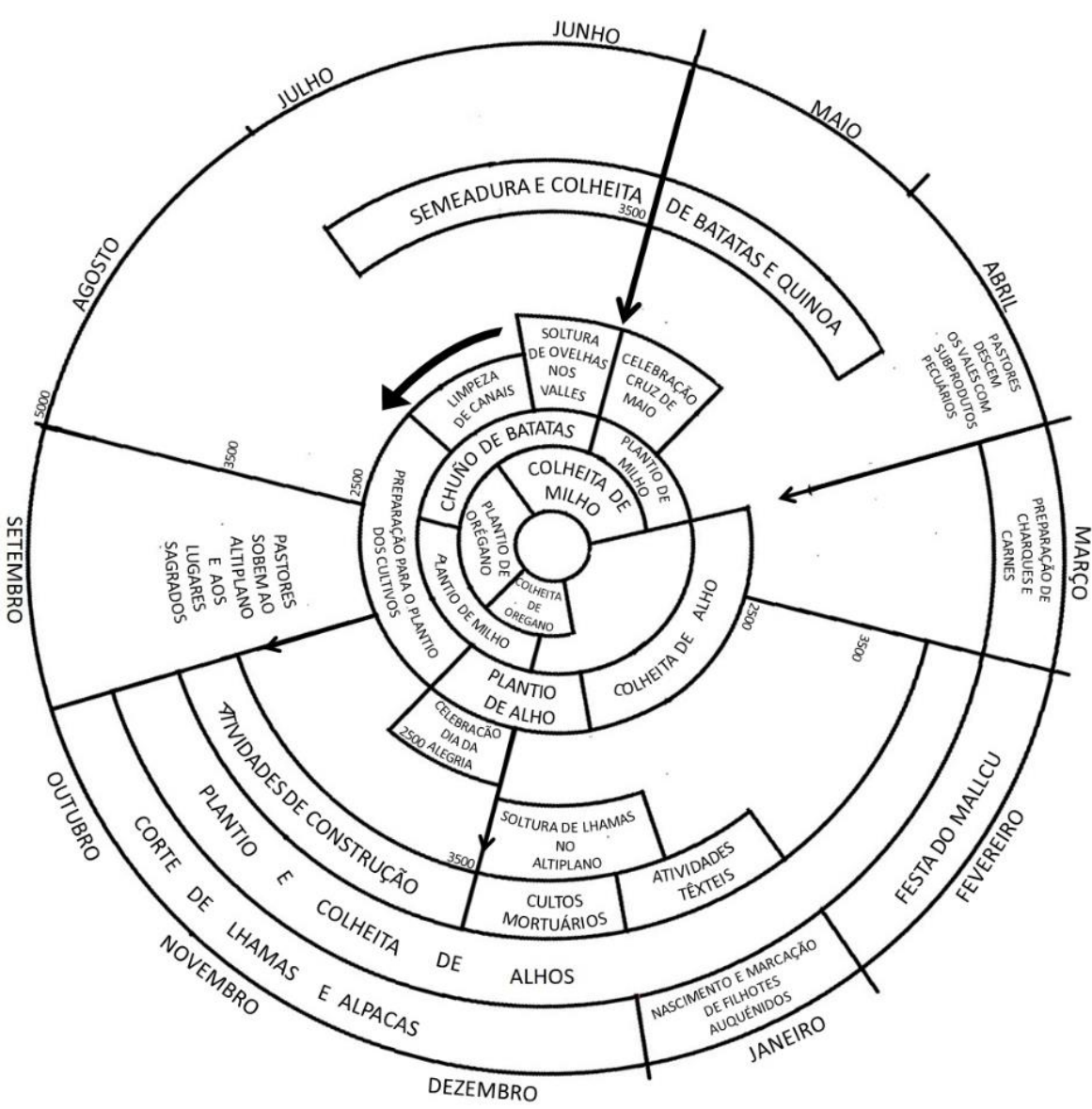

Figura 2 - Calendário de tarefas agrícolas e pastoris das comunidades Aymaras do norte do Chile. Fonte: Adaptado de Van Kessel (1992).

\section{TOPOCLIMATOLOGIA, REDES HIDROSSOCIAIS E A MINERAÇÃo DE LÍTIO NO SALAR DE ATACAMA}

O Chile é um dos principais detentores de reservas e o maior produtor de lítio do mundo (GRUBER, et al., 2011). A maior parte se encontra no Salar de Atacama (Figura 3), no coração do Deserto do Atacama, localizado na précordilheira andina da região de Antofagasta, a mais de $2.300 \mathrm{~m}$ de altitude. Este lugar reúne características biofísicas e culturais únicas: insolação e evaporação máxima que transformam em salmoura os fluxos líquidos superficiais e subterrâneos de água que transportam os sais minerais infiltrados nos aquíferos; ocorrência de chuvas de verão em ecossistemas específicos localizados nos níveis de maior altura, e presença de estepes vegetais altoandinos e matas arbustivas que facilitam a infiltração e controlam o escoamento das águas da chuva (KAVANAGH et al., 2018). Nesta região estão presentes também culturas atacamenãs da etnia Likantay, que construíram redes e territórios hidrossociais que garantiram a conservação das paisagens que são fonte de água, além de fortalecer a continuidade espacial dos fluxos (superficiais e subterrâneos), seus usos (e não usos) em atividades agrícolas, pastoris e rituais baseados na propriedade comunitária mediante às 
organizações dedicadas à proteção e distribuição dos recursos hídricos (ROMERO, et. al., 2018).

O lítio é um mineral não metálico usado principalmente em baterias para armazenar eletricidade. Seu uso pelo setor automotivo e de telecomunicações é enorme e cresce cada vez mais. Como consequência, a demanda dos mercados consumidores globais vem aumentando gradual e permanentemente (KAVANAGH et al., 2018). O governo chileno, proprietário dos depósitos de lítio, os arrenda ou os concede a empresas nacionais e estrangeiras que necessitam para extração e processamento, grandes quantidades de água que, por sua vez, é o recurso mais escasso nessas regiões e pertence às comunidades indígenas, além de ser fundamental para o sustento de áreas de proteção da natureza como parques nacionais e reservas naturais. Atualmente, existem conflitos sobre a propriedade e uso da água entre comunidades ancestrais, empresas de mineração, organismos responsáveis pela conservação da natureza e agentes turísticos, já que a área é uma das maiores atrações do país.

$\mathrm{Na}$ região de Antofagasta as áreas montanhosas sob condições áridas extremas compõem a geoforma dominante na maior parte do território. Entretanto, as condições climáticas e ecológicas do deserto absoluto são interrompidas pela presença da bacia do rio Loa que transporta águas desde as montanhas andinas até o desague no litoral. A outra geoforma expressiva é a grande bacia do Salar de Atacama, onde vários riachos levam águas andinas das terras mais altas até um grande lago salinizado, resultado da forte aridez do ambiente.

Como em todo o Deserto do Atacama, os altiplanos andinos desempenham o papel de "torres de água" constituídas por altas montanhas e vulcões que provocam chuva e acúmulos de neve associados à atividade da monção amazônica (MENDONÇA, 2017). Essas águas escorrem superficialmente através de múltiplos canais e são temporariamente depositadas em numerosas terras úmidas, lagos e lagoas, algumas das quais são remanescentes paleoclimáticos, ou seja, originadas há milhares de anos como fontes de água doce e transformadas em água salgada como consequência da alta evaporação registrada em longos e sucessivos períodos de câmbios climáticos desde o Holoceno.

No norte da região de Antofagasta há um conjunto de salinas denominadas Michincha, Acostán e Carcote. Estas salinas abasteceram historicamente a exploração mineral e, ainda hoje, sustentam ecossistemas de extraordinários valores ecológicos em torno dos quais comunidades ancestrais foram estabelecidas. No centro da região, a leste do Salar de Atacama, ocorrem as salinas de Tara, Pucsa, Loyoques, Aguas Calientes, El Laco, Cepúr e Talar. No sul da região, as salinas de Punta Negra e Pajonales são encontradas. De modo geral, todos elas sustentaram a produção de minérios, foram e são objeto de lutas entre comunidades, agências estatais e empresas de mineração.

A distribuição espacial dos projetos de investimento, especialmente os de mineração, ocorre sobre a depressão intermediaria entre o córrego Los Arrieros e o Salar de Pampa Blanca na região norte, os riachos Lá Negra e Las Zorritas no centro, e os riachos La Negra, Pan de Azúcar e Juncal no sul. Outras importantes zonas de mineração estão localizadas na bacia do rio Loa, principalmente no entorno do oásis de Calama, enquanto que os depósitos de 
lítio e potássio estão no interior do Salar de Atacama. A Figura 3 apresenta os projetos de investimento instalados na região entre 2006 e 2017.

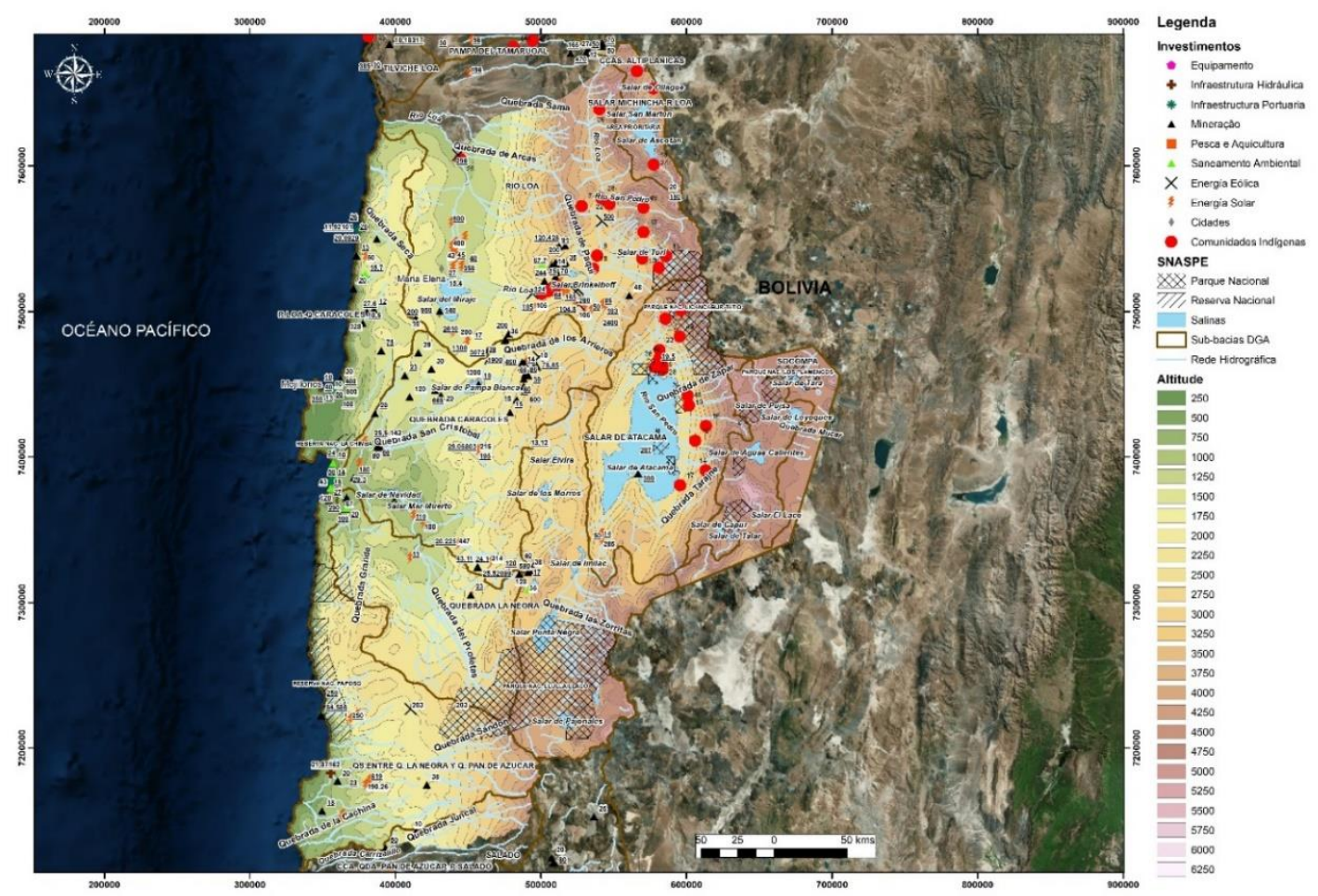

Figura 3 - Projetos de investimento (2006-2017), Sub-bacias, Áreas Silvestres Protegidas (SNASPE), Comunidades indígenas e Salinas da região de Antofagasta - Chile. Fonte: Elaborado pelos autores com base nos dados do SEA, 2016.

Para sustentar a produção mineral, extrações de água se localizam nas salinas altiplanicas do norte da região (Ollagüe, San Martín, Ascotán) cujos direitos foram historicamente solicitados por empresas privadas e pelo Estado. Algumas destas zonas são consideradas como áreas prioritárias para a conservação da biodiversidade. Há também comunidades indígenas nos arredores das salinas. A Figura 4 apresenta os solicitantes dos direitos sobre as águas subterrâneas entre 1990 e 2017 em toda a área de estudo. 


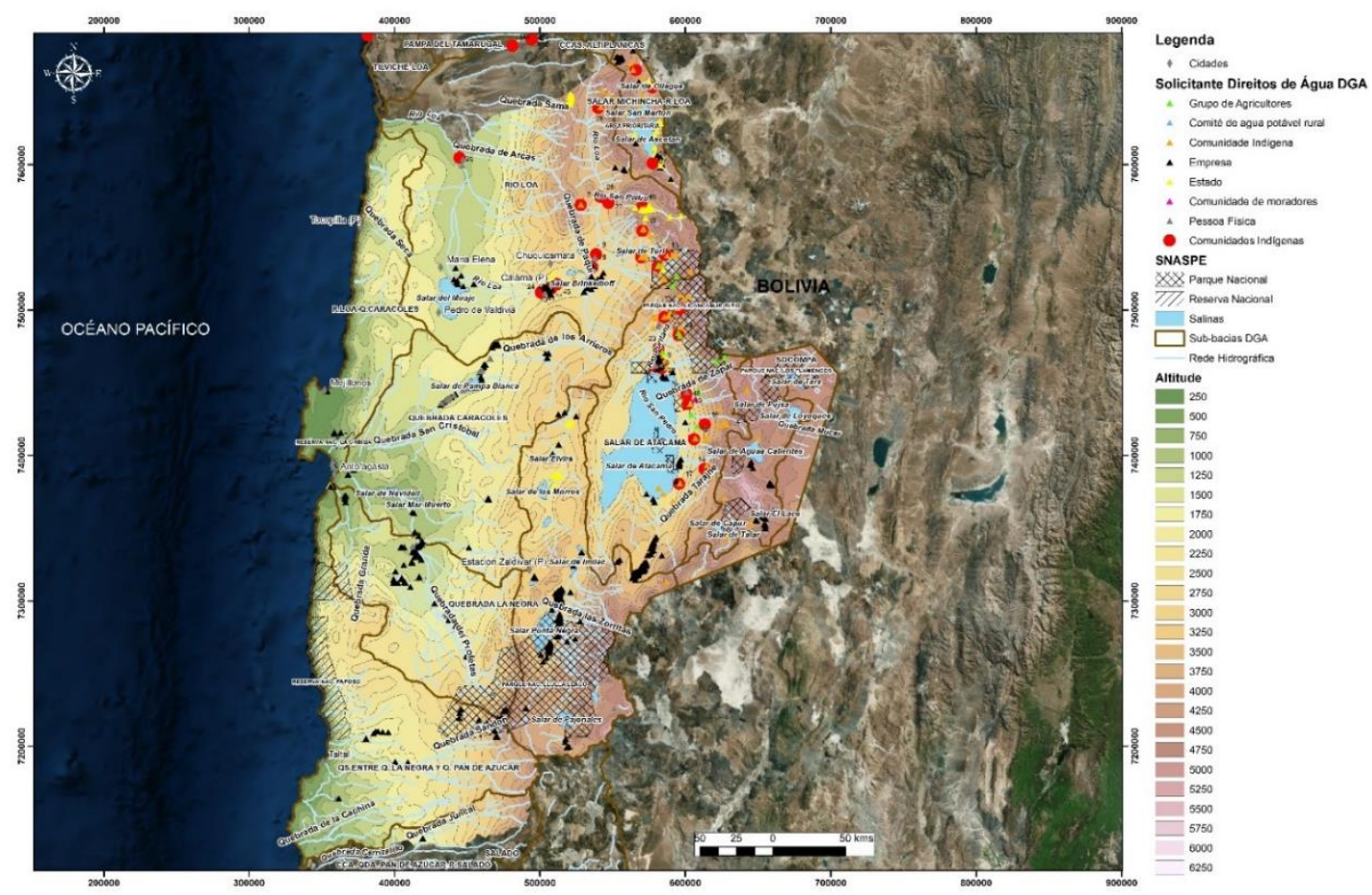

Figura 4 - Solicitantes de direitos de água subterrânea (1990-2017), Sub-bacias, Áreas Silvestres Protegidas (SNASPE), Comunidades indígenas e Salinas da região de Antofagasta - Chile. Fonte: Elaborado pelos autores com base nos dados do DGA, 2018 e IDE, 2015.

Na bacia de Loa as principais extrações se localizam ao redor dos rios Loa, San Pedro e las Vegas, além do Salar de Turi e do oásis de Calama. Envolvem as comunidades indígenas, o Estado, as associações de agricultores e empresas privadas. Conchi Viejo, Ojos de San Pedro e Taira são algumas comunidades que compõem um agrupamento ao longo dos rios San Pedro e Chunchuqui, enquanto que Tankara e Loa de la Banda são exemplos que estão localizados no entorno do oásis calamenõ.

Como em todo o norte do Chile, também são notadas superposições territoriais entre áreas de conservação da natureza e de assentamentos de comunidades indígenas. Na região de Antofagasta esse problema é encontrado entre a área do Parque Nacional Lincancabur - El Tatío e as comunidades indígenas localizadas em seu interior e/ou bordas imediatas, como Caspana, Toconce, Machuca, Rio Grande e Guatín. Há décadas essas comunidades lutam contra agentes externos para conservar suas redes e territórios sóciohidrológicos.

Um grupo de dezoito comunidades indígenas que residem nas margens do Salar de Atacama conformam o Conselho de Povos Atacameños, encarregado da defesa de seus territórios e, em particular, das águas que descem dos relevos vulcânicos e que cercam a bacia. O controle espacial das sub-bacias foram e continuam sendo uma fonte permanente de conflitos socioterritoriais entre as comunidades, $o$ Estado e as empresas mineradoras nacionais e estrangeiras. Nos últimos anos, acordos econômicos foram realizados entre as 
comunidades e as empresas, de modo que as primeiras passaram a obter uma fração dos lucros que, teoricamente, compensam com dinheiro os danos socioambientais. A Figura 5 apresenta os solicitantes dos direitos sobre as águas subterrâneas e a vazão estimada em toda a área de estudo.

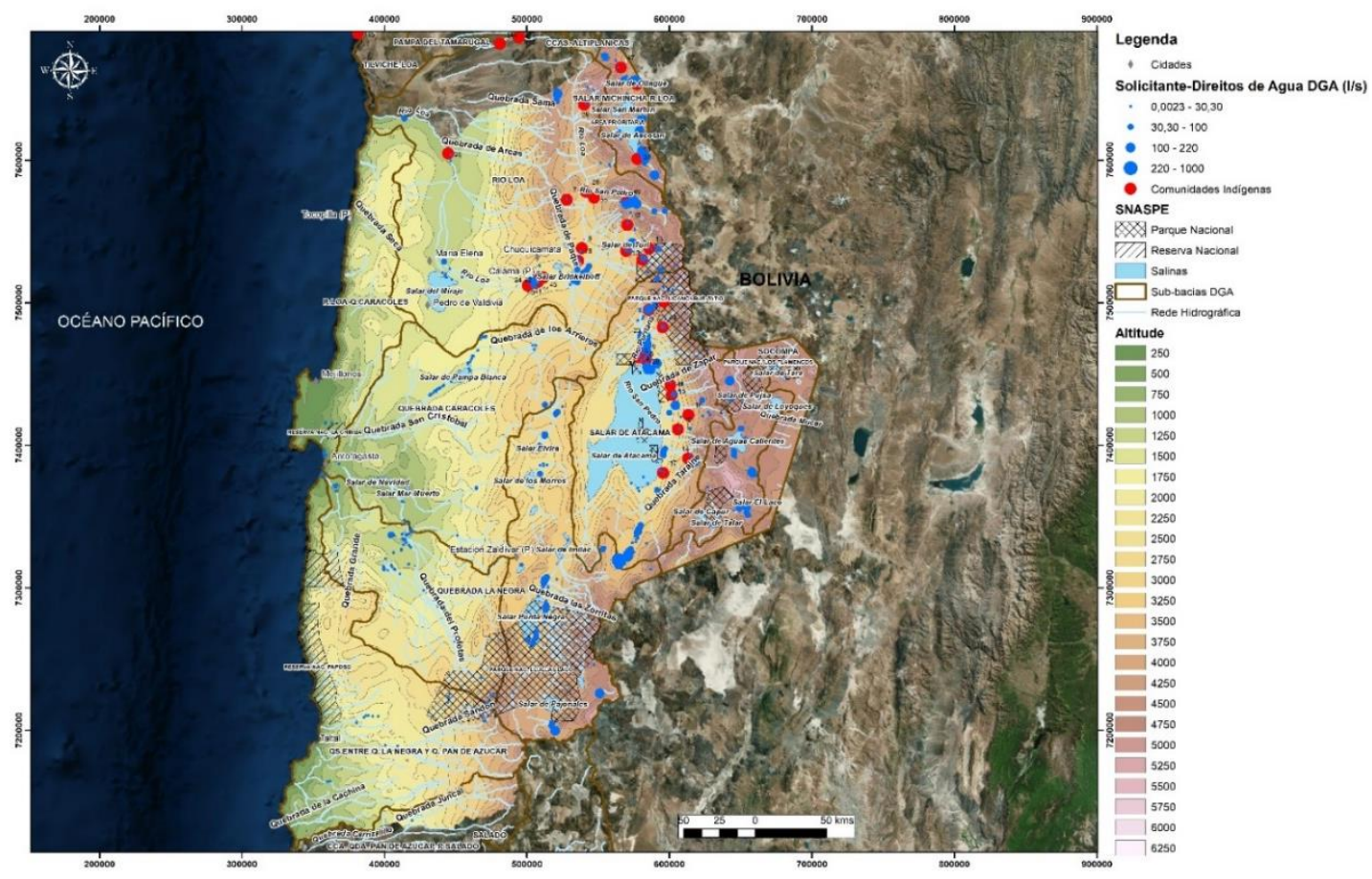

Figura 5 - Solicitantes de Direitos de água subterrânea e vazão estimada (1990-2017), sub-bacias, Áreas Silvestres Protegidas (SNASPE), comunidades indígenas, lagos e salinas da região de Antofagasta - Chile. Fonte: Elaborado pelos autores com base nos dados do DGA, 2018 e IDE, 2015.

A localização das comunidades do Salar de Atacama conforma padrões espaciais. Cabe distinguir aquelas que estão agrupadas ao longo de parte do leito do rio (San Pedro de Atacama, Sequitor, Checar, Solor e Cuter), e aquelas que se localizam separadamente em alguma seção de uma sub-bacia: Machuca, Guatín, Caparte, Camar, Talabre e Socaire no curso médio, e Toconao e Peine na foz das sub-bacias do Salar. Por outro lado, também é importante considerar a presença de comunidades indígenas no interior ou nos arredores de áreas de proteção da natureza, como ocorre na área do Parque Nacional LincancaburTatio (Machuca, Rio Grande, Guatín), e no entorno de vários trechos que compõem a Reserva Nacional Los Flamencos (Toconao).

As áreas cordilheiranas de extração de águas se localizam nas margens norte, leste e sul do Salar de Atacama, áreas estas que correspondem também a um grupo de requerentes sobrepostos nos mesmo territórios. Sobreposições similares são encontradas entre áreas de conservação e de extração mineral, como as salinas altiplanicas (principalmente Águas Calientes e El Laco) que formam parte da Reserva Nacional Los Flamencos e o Parque Nacional Llullaillaco, localizado ao sul da região. Por fim, salinas e córregos localizados na depressão intermediária e que armazenam ou transportam as águas em forma superficial ou subterrânea como El Miraje, Pampa Blanca, del Muerto, Profeta e Ano 15 - Edição Especial - XIII Simpósio Brasileiro de Climatologia Geográfica - JUN 2019 
La Negra, estão sujeitos às extrações pelas empresas de mineração que operam na área. A Figura 6 apresenta os investimentos econômicos, os solicitantes dos direitos de uso de água subterrânea e as áreas de preservação no Salar de Atacama e seu em entorno imediato.

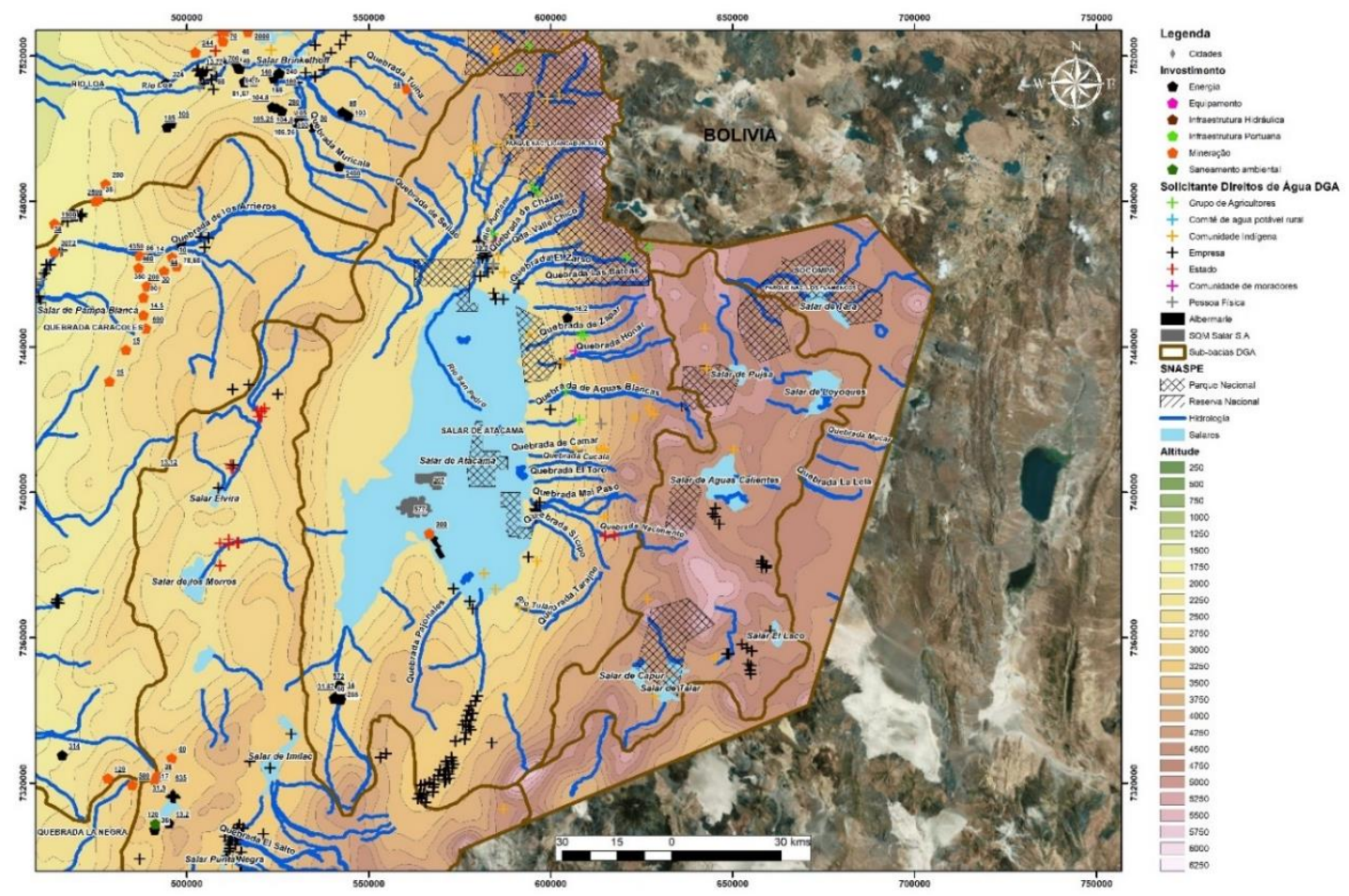

Figura 6 - Investimentos econômicos e Solicitantes dos direitos de uso de água subterrânea no Salar de Atacama e entorno - norte do Chile. Fonte: Elaborado pelos autores com base nos dados do DGA, 2018 e IDE, 2015.

\section{CONSIDERAÇÕES FINAIS}

A Geografia Física Crítica constitui uma oportunidade para compreender os problemas complexos que caracterizam o antropoceno e que se manifestam em ações e paisagens geográficas especificas, tal como ocorre com a exploração de lítio no Salar de Atacama, em meio ao deserto mais árido do mundo, onde a água alcança seu mais alto valor ecológico, físico, material, cultural e espiritual. Entre os numerosos aportes dessa forma de fazer geografia centrada na coprodução de conhecimento entre a academia e os atores sociais, estão integrados os componentes biogeofisicos do território, juntamente com as expressões culturais e sociopolíticas considerando a forma (metodologia) de produzir conhecimentos (epistemologia) e de compreender seus significados (ontologia) a partir das comunidades locais.

Esta Geografia propõe conceitos como topoclimatologia cultural, sociogeomorfologia e redes e ciclos hidrossociais como construções hibridas que pretendem elaborar conhecimentos a partir de perspectivas mais complexas e amplas que a simples separação entre geográfica física e humana, além dos diferentes objetos que são estudados por cada uma das especializações que as compõem. Os propósitos destas aproximações consistem em contribuir para 
consolidar a condição da geografia como ciência social, distanciá-la do reducionismo e positivismo cientifico, além de questionar a aplicação de modelos numéricos e cosmopolitas não situados espacial e culturalmente.

Não obstante, se trata também de colocar a serviço das comunidades sociais em geral e dos povos indígenas andinos, em particular, conhecimentos que possam contribuir como argumentos para as discussões políticas na defesa de seus territórios. Isso se torna particularmente relevante diante das crescentes ameaças por parte dos estados e empresas transnacionais em apoderar-se de seus recursos naturais, desarticular as estruturas e redes sociais e priva-los de seus territórios, modos de vida e sistemas de valores tradicionais.

A Geografia Física Crítica não significa apenas uma tentativa de renovar a disciplina, mas também de dotá-la de um autêntico sentido social que, sobre os princípios e valores humanísticos, contribua para confrontar modelos de desenvolvimento que eliminam os valores da virtude, solidariedade, reciprocidade, justiça e equidade. Estes valores caracterizam as relações entre os seres humanos e não-humanos de paisagens indígenas, que vem sendo paulatinamente extintos dos territórios andinos, sufocados pela globalização.

Sendo a água o recurso mais escasso e relevante no Deserto do Atacama, a organização dos territórios ligados às bacias hidrográficas sustenta as relações e redes sóciohidrológicas, expressas por disputas de poder entre os principais atores sociais, focados no domínio e controle das fases do ciclo hidrológico: áreas de captura e infiltração das chuvas e neves nos trechos altos, escoamento superficial e subterrâneo nos cursos médios e deposição dos mesmos em lagos, várzeas e salinas.

Cada geoforma significa uma relação complexa entre componentes biogeofísicos e culturais. Além disso, sua propriedade e controle é uma questão política de controvérsia permanente entre diferentes ordens territoriais. Os territórios ancestrais tentam manter sistemas produtivos, conservação de solo e água, manutenção de circuitos de transumância e modos de vida que significam a promoção da vida entre componentes humanos e não humanos. A topoclimatologia coopera com tal ideia, considerando a distribuição das formas climáticas locais e sua associação com práticas socioeconômicas, rituais e culturais. Água, climas e geoformas não podem ser analisados independentemente ou separadamente dos sistemas de conhecimento, significado e gestão realizados pelas comunidades locais.

Finalmente, a Geografia Física Crítica constitui então em uma efetiva proteção dos territórios andinos diante do ataque do capital e da ciência externa, na medida em que todas essas intervenções visam a extração de recursos e o enriquecimento material de agentes estrangeiros. A indústria do lítio constitui uma fase recente da tentativa de despojar os recursos ambientais das comunidades que habitam o Salar de Atacama. A oposição ética, científica e política a tais tentativas confronta cada vez mais com a transformação das paisagens em mercadorias e o uso da compensação financeira como o único argumento na tomada de decisões. 


\section{AGRADECIMENTOS}

Em especial à Rede Macro de Universidades da América Latina e Caribe pela bolsa de estudos que proporcionou a viagem, estadia e parceria de trabalho entre o Programa de Pós-Graduação em Análise e Modelagem de Sistemas Ambientais do IGC/UFMG e a FAU/Universidad de Chile. Agradecimentos também à coordenação do PPG-AMSA do IGC/UFMG pela permissão e incentivo de realização da mobilidade acadêmica.

\section{REFERÊNCIAS BIBLIOGRÁFICAS}

ASHOMORE, P. Towards a sociogemorphology of rivers. Geomorphology, $\mathrm{n}$. 251, p. 149-156, 2015.

BABIDGE, S. Water, mining and indigenous people in the Atacama Desert. The Australian Journal of Antropology, n. 27, p. 84-103, 2016.

BOELENS, R. Cultural Politics and the Hydrosocial Cycle: Water, Power and Identity in the Andean Highlands. Geoforum, n. 57, p. 234-247. 2014.

BOELENS, R.; HOOGESTEGER, J.; SWYNDEGOUW, E.; VOS, J.; WESTER, P. H. Hydrosocial Territories: A Political Ecology Perspective, Water International v. 42, n. 1, p. 1-14, 2016.

BUDDS, J. The 1981 Water Code: The Impacts of Private Tradable Water Rights on Peasant and Indigenous Communities in Northern Chile. In: Lost in the Long Transition: Struggles for Social Justice in Neoliberal Chile. Lanham: Lexington Books, 2009, p. 41-62.

BUDDS, J. Water Rights, Mining and Indigenous Groups in Chile's Atacama. In: Out of the Mainstream: Water Rights, Politics and Identity. Londres: Earthscan, 2010, p. 197-212.

CASTREE, N. Geography and the new social contract for global change research. Transactions of the Institute of British Geographers, n. 31, p. 328347. 2016.

GOUDIE, A. The integration of Human and Physical Geography Revisited. The Canadian Geographer, v. 61, n. 1, p. 19-27, 2017.

DGA. Dirección General de Agua del Ministerio de Obras Públicas. Derechos de aprovechamientos de aguas registrados en DGA - 2018. Disponível em: <http://www.dga.cl/productosyservicios/derechos_historicos/Paginas/default.as px>. Acesso em: junho. 2018.

GREBE, M. E. Concepción del tiempo en la cultura Aymara: representaciones icónicas, cognición y simbolismo. Revista Chilena de Antropología, v. 9, p. 6381, 1990.

GRUBER, P.W.; MEDINA, P.A.; KEOLEIAN, G.A.; KESLER, S.E.; EVERSON, M.P.; WALLINGTON, T. J. Global lithium availability. Journal of Industrial Ecology, $v$. 15, p. 760-775, 2011.

HULME, M. Weathered: Cultures of Climate. Reino Unido: SAGE, 2017. 200 p.

HULME, M. 2015. Climate and its Changes: A cultural Appraisal. Geo: Geography and Environment, v. 2, n. 1, p. 1-11, 2015. 
IDE. Infraestructura de Datos Espaciales. Sistema Nacional de Áreas Silvestres Protegidas del Estado (SNAPSE) - 2015. Disponível em: <http://www.ide.cl/descarga/capas/item/sistema-nacional-de-areas-silvestresprotegidas-delestadosnaspe.html>. Acesso em: junho 2018.

KAVANAGH, L; KEOHANE, J.; CABELLOS, G. G.; LLOYD, A.; CLEARY, J. Global Lithium Sources - Industrial Use and Future in the Electric Vehicle Industry: A Review. Resources, v. 7, n. 57, p. 2-29, 2018.

KERSHAW. G.; CASTLEDEN, H.; LAROQUE, C. An argument for ethical physical geography research on indigenous landscapes in Canada. The Canadian Geographer, v. 58, n. 4, p. 393-399., 2014.

LAVE, R.; WILSON, M.; BARRON, E; BIERMAN, C.; CAREY, M. DUVALL, C. JOHSON, L.; LAINE, M.; MCCLICKTON, M.; MUNROE, D.; PAIN, R. POCTOR, J.; RHOADS, B.; ROBERTSON, M.; SIMON, G.; TADAKI, M.; VAN DICK, C. Intervention: Critical Physical Geography. The Canadian Geographer, v. 58, n. 1, p. 1-10, 2014.

LINTON, J. What is water? The History of a Modern Abstraction. Toronto: The University of British Columbia Press, 2010, 464 p.

LINTON, J.; BUDDS, J. The Hydrosocial Cycle: Defining and Mobilizing a Relational-Dialectical Approach to Water. Geoforumn v. 57, p. 170-180, 2014.

MÉNDEZ, M., ROMERO, H. Construcción de los territorios altoandinos de Tarapacá, norte de Chile. Reflexión conceptual desde una perspectiva históricogeográfica. Revista Chilena de Antropología, v. 37, p. 183-196, 2018.

MENDONÇA, M. Monzón sudamericano: la integración de la circulación amazónica y altiplánica y las variabilidades climáticas del altiplano andino chileno. Diálogo Andino, v. 54, p. 21-30, 2017.

MENDONÇA, M.; ROMERO, H.; OPAZO, D. Análise multiescalar para a comprenssao de causas e consequências da variabilidade climática na américa do sul. In: Experimentos em climatología geográfica. Brasil: Universidade Federal da Grande Dourados (UFGD), 2014, p. 271-290.

POPKE, J. The Spaces of Being In-Common: Ethics and Social Geography. In: The Handbook of Social Geography. London: Sage, 2010, Cap. 4, p. 435-455.

POPKE, J. Researching the Hybrid Geographies of Climate Change: Reflections From the Field. Area, v. 48 n. 1, p. 2-6, 2016.

PRIETO, M.Transando el agua, produciendo territorios e identidades indígenas: el modelo de aguas chileno y los atacameños de Calama. Revista de Estudios Sociales, v. 55, p. 88-103, 2016.

ROMERO, H., SMITH, P., MENDONCA, M., MENDEZ, M. Macro y mesoclimas del Altiplano Andino y Desierto de Atacama: Desafíos y estrategias de adaptación social ante su variabilidad. Revista de Geografía Norte Grande, v. 55, p. 19-41, 2013.

ROMERO, H.; ESPINOZA, G.; OPAZO, D.; SEPULVEDA, D. Topoclimatología cultural y cambios de clima en la zona andina del Norte de Chile. In: Reconociendo las Geografía de América Latina y El Caribe. Chile: Instituto de Geografía de la Pontificia Universidad Católica de Chile, 2017, P. 93-131. 
ROMERO, H.; ROMERO TOLEDO, H.; OPAZO, D. Topoclimatología cultural y ciclos hidrosociales de comunidades andinas chilenas: Híbridos geográficos para la ordenación de los territorios. Cuadernos de Geografía: Revista Colombiana de Geografía, v. 27, n. 2, p. 242-261, 2018.

SEA. Servicio de Evaluación Ambiental. Inversiones - 2016. Disponível em: <http://seia.sea.gob.cl/busqueda/buscarProyecto.php>. Acesso em: junho 2018.

SLAYMAKER, O. Physical geographers understanding of the real world. The Canadian Geographer, v. 6, n. 1, p. 64-72, 2017.

TADAKI, M. Rethinking the role of critique in physical geography. The Canadian Geographer, v. 61, n. 1, p. 73-83, 2017.

TADAKI, M.; VAN DICK, C. Intervention: Critical Physical Geography. The Canadian Geographer, v. 58, n. 1, p. 1-10, 2014.

VAN KESSEL, J. 1992. La organización temporo espacial del trabajo entre los Aymaras de Tarapacá: la perspectiva mitológica. In: Etnicidad, Economía y Simbolismo en los Andes. Lima: Institut français d'études andines, 2002, p. 267-297.

VAN KESSEL, J.; SALAS, P. E. Señas y señaleros de la santa tierra: agronomía andina. 4 ed. Quito-Santiago: Abya-Yala-IECTA. 2002, p. 307 